\title{
SOCWARE: A NEW SWEDISH DESIGN CLUSTER FOR SYSTEM-ON-CHIP
}

\author{
Peter Nilsson ${ }^{1}$, Petru Eles ${ }^{2}$, and Hannu Tenhunnen ${ }^{3}$ \\ ${ }^{1}$ Department of Electro Science, Lund University \\ ${ }^{2}$ Department of Computer and Information Science, Linköping University \\ ${ }^{3}$ Department of Electronics, Royal Institute of Technology \\ peter.nilsson@tde.lth.se,petel@ida.liu.se,hannu@ele.kth.se
}

\begin{abstract}
Socware is the name for a new design cluster in Sweden, which intends to unify university, research institutes, and industry towards a common goal, namely System-on-Chip. In this paper, one of the programs within the cluster, the Socware Research \& Education Program, is presented. The program aims to organize a new education curriculum for System-on-Chip design. The education is directed to undergraduate and graduate students as well as Master's in industry. Totally, the Socware Design Cluster has $50 \mathrm{M} €$ of public funds, where $15 \mathrm{M} €$ are reserved for the Socware Research \& Education program.

\section{INTRODUCTION}

Today, a dramatic change in circuit and system design is seen. The number of transistors has increased to numbers where it is feasible to implement a complete system on a single chip. Therefore, new education profiles are discussed in both Europe and the US, in for instance [1].

The new "System-on-Chip ware" (Socware) initiative intends to maintain Sweden as one of the leading actors in the System-on-Chip area. To achieve that, Socware is organized as a cluster where industry, research institutes, and universities act together. The Socware Design Cluster [2] consists of four programs:
\end{abstract}

- Socware Research \& Education program

- Acreo SLI Center

- Socware IPR Management program

- Socware Business Development program.

This paper presents the first of these programs, namely the Socware Research \& Education program [3]. The general goal for the program is to strengthen the research and education activities in microelectronics system design in Sweden. With a common goal aiming at System-on-Chip methodology, various activities will be used to strengthen the research and education. Support of faculty positions, long-term graduate student projects, and undergraduate education as well as short industry courses are the main examples of these activities.

Today, the program has three Swedish university The Socware education will give the students more interpartners located in Linköping, Lund, and Stockholm and one disciplinary skills than a regular EE curriculum, as illustrated research institute partner, Acreo $\mathrm{AB}$ in Norrköping. The in figure 1. These skills are needed for the design of three universities will conduct the undergraduate and embedded systems consisting of analog/RF ASICs, digital

graduate programs and the research institute is responsible for short courses offered to the industry.

First of July 2000 was the starting date for the Research $\&$ Education program. Initially, the program has focused on education of students at Master of Science level. In the first year, 70 students have registered for the program. An increase to $100-150$ is expected.

\section{SOCWARE EDUCATION}

The first task for the program is to support and unify a new curriculum in the Swedish master's programs. The new curriculum is motivated by the dramatic change in design methodology. For the past 20 years, ASIC design has been dominated by design of single functions or single cores. Future ASIC design methodology will be based on design of systems where major parts will be placed on the same silicon die. The ASIC design will thus be based on design of cores or IP blocks, which are interacting on chip.

The new curriculum, based on System-on-Chip design, will be open for master students at Swedish universities and bachelors graduated at local Swedish university colleges. The education will also be open for international bachelors. Students who graduate from the Socware education will receive a master degree.

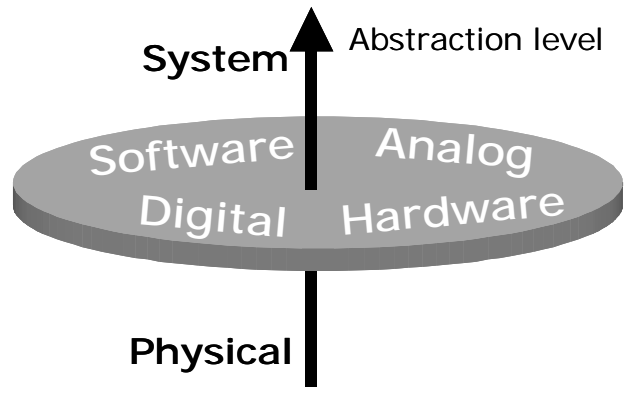

Figure 1: The Socware curriculum is a wide curriculum, which covers analog-digital as well as hardware-software aspects. The education is also deep to give skills on all abstraction levels. 
ASICs, and embedded software. Each student will be expected to master at least two domains, including their interfaces.

A skilled Socware student will know how to partition a system and be able to make a trade-off between solutions based on the different domains. To this end, all abstraction levels from system level specifications down to the circuit level and physical limitations including modeling from one domain to another will be included in the Socware curriculum. Four areas are identified to be common in the curriculum.

- Circuits

- Digital, mixed signal, and analog ASICs

- System aspects - coupling and interconnection

- $\quad$ System and architectures

○ System design methodology

- System modeling

- Embedded software

- Hardware descriptions - synthesis

- SoC architectures

- $\quad$ Projects

- Practical hands on - silicon projects which are fabricated and verified

- $\quad$ IPR issues

- Copyright, design protection, and patent law

The program starts at bachelor level and consists of 40 Swedish credit units of courses, which corresponds to a one year study program, which is followed by a 20 -credit units thesis work, corresponding 6 to months. With this schedule, the first Socware Engineers will be graduated at the end of year 2001.

\section{SOCWARE RESEARCH}

The second task for the program will be to support graduate student projects. System-on-Chip design is one of the most expansive areas today. The expansive nature attracts most of the Master students to industry and the situation for university recruitment of graduate students has become very difficult.

At the end of 2001, the first Master's are graduated. These students have been studying more closely to the research groups that also conduct the teaching in the System-on-Chip area. One of the aims for the program is that the close connection between researchers and students shall improve the recruitment situation. A System-on-Chip research program is therefore under development to give a continuation from undergraduate to graduate level.

The program will also support faculty staff. Most funding sources in Sweden do only finance the students but to succeed with both the undergraduate and the graduate student programs it is crucial to increase the faculty resources.

\section{SOCWARE SHORT COURSES}

Education of engineers working in the area of circuit and system design is requested by the industry. Therefore, a short course program based on System-on-Chip design methodology is planed. The research institute, Acreo AB, is responsible for planning the program together with the university researchers. Courses from 2-3 days up to 1-2 weeks are feasible.

\section{CO-ORDINATION}

The program is co-ordinated by the Socware Research \& Education program committee. The committee has representatives from industry such as Ericsson and Nokia as well as university representatives. The reason for a national committee is both to guarantee that the education curriculum is unified at the three universities and to see that the industry relevance is kept.

The Socware Research \& Education Program has financial support from three sources:

- The Swedish Ministry of Industry supports the research and education activities at the three universities with approximately $11 \mathrm{M€}$.

- The KK foundation supports the management of the program with approximately $1 \mathrm{M} €$.

- The Swedish Ministry of Education supports with 100 new undergraduate student places corresponding to approximately $3 \mathrm{M} €$.

The total of $15 \mathrm{M} €$ will guarantee financial support of the Socware Research \& Education program in 5 years.

\section{CONCLUSIONS}

A new Swedish research \& education program for Systemon-Chip design methodology is presented. The program aims to give an interdisciplinary master education in circuit and system design. The graduated student is expected to master several domains in the area of analog/RF, mixed signal, and digital ASICs. The education also focuses on hardware and embedded software aspects in silicon design. An important goal is also to give an education on all abstraction levels, from physical level up to system level.

\section{REFERENCES}

[1] Hugo de Man, "System-on-Chip Design: Impact on Education and Research", IEEE Design \& Test of Computers, pp. 11-19, July-September1999

[2] www.socware.com

[3] www.tde.lth.se/socware 